\title{
Early or late appearance of "dropped head syndrome" in amyotrophic lateral sclerosis
}

\author{
M Gourie-Devi, A Nalini, S Sandhya
}

J Neurol Neurosurg Psychiatry 2003;74:683-686

Background: "Dropped head syndrome" caused by neck extensor weakness has been reported in a variety of neuromuscular disorders. Previously published reports include isolated cases with amyotrophic lateral sclerosis (ALS). In this report, nine patients with ALS and dropped head syndrome seen during a 20 year period are described.

Patients and investigations: Between 1981 and 2000, 683 patients with ALS were diagnosed, based on El Escorial criteria. Nine of these had profound neck extensor weakness observed as an early feature, or developing during the later stages of the disease. The protocol for evaluation included detailed clinical history, neurological examination, electromyography, and nerve conduction studies. Investigations were undertaken to exclude malignancy, lymphoproliferative disorders, thyroid dysfunction, and collagen vascular disease.

Results: The incidence of dropped head syndrome was $1.3 \%$. The mean (SD) age of the affected patients was 53.3 (10.3) years (range 33 to 65), with an equal distribution of cases in the fourth to seventh decades. In six patients, head drop was an early feature (mean interval from onset of illness 11.6 months (range 3 to 24)); in three it was late (between three and eight years after onset). In five patients, mild neck flexor weakness was present in addition to severe extensor weakness. In all nine patients there were diffuse upper and lower motor neurone signs. None of the patients had difficulty in breathing but all had difficulty in swallowing and social embarrassment, both of which could be corrected by simple measures.

Conclusions: Dropped head syndrome is an important clinical sign and usually occurs as an early feature within the first one to two years after the onset of ALS. The cause of dropped head syndrome in these nine cases could be easily established as ALS by the presence of generalised signs.

S evere weakness of the neck extensor muscles with "dropped head syndrome" has been described in various neuromuscular disorders. This syndrome, characterised by weakness of the extensor muscles of neck with or without involvement of neck flexors, can be caused by a myogenic or neurogenic process and has been observed in myasthenia gravis, ${ }^{1}$ inflammatory myopathy, ${ }^{2}$ amyotrophic lateral sclerosis (ALS), ${ }^{3}$ facio-scapulo-humeral dystrophy, ${ }^{4}$ nemaline myopathy, ${ }^{5}$ carnitine deficiency, ${ }^{6}$ and spinal muscular atrophy. ${ }^{78}$ Recently a new disorder, "isolated neck extensor myopathy", caused by a non-inflammatory myopathy has been identified as a common cause of dropped head syndrome in elderly people. ${ }^{78}$

There are only a few case reports of dropped head syndrome in ALS. ${ }^{8-11}$ During a period of 20 years (1981 to 2000) we have seen nine patients with ALS who had dropped head syndrome owing to severe weakness of the cervical paraspinal muscles.

\section{METHODS}

During the period of 20 years from 1981 to 2000, 683 patients with ALS were seen at the National Institute of Mental Health and Neurosciences, Bangalore, southern India-a major tertiary referral centre for neurological disorders. Nine of these had profound neck muscle weakness with head drop, noticed as an early feature or developing during the later stages of the disease.

El Escorial criteria for the diagnosis of ALS were used. The protocol included detailed clinical history, neurological examination, electromyography, and nerve conduction studies. Appropriate neuroimaging studies were done when indicated. Relevant investigations to look for evidence of malignancy, lymphoproliferative disorders, thyroid dysfunction, and collagen vascular disease were undertaken. Disability as of the last follow up examination was recorded.

\section{RESULTS}

The nine patients with neck muscle weakness formed $1.3 \%$ of the total group of 683 ALS patients. They comprised six men and three women, with a mean (SD) age of 53.3 (10.3) years (range 33 to 65) (table 1). There was an almost equal distribution of the patients in the fourth to seventh decades. At onset, eight of them had symptoms in the limbs and one had bulbar symptoms. The neck muscle weakness with head drop was seen at varying intervals after the onset of limb weakness or bulbar symptoms, ranging from three months to eight years (mean 28 months), and was not a presenting symptom. It is pertinent to note that in six of the nine patients (cases 1, 2, 4, 6,7 , and 9), neck weakness was a relatively early feature, occurring at a mean of 11.6 months (range 3 to 24 months) after the onset of the illness. In only three cases (Nos 3, 5, and 8) was neck extensor weakness a late feature, appearing between three and eight years after the onset of the illness.

Five patients (cases 2, 3, 4, 6, and 7) complained of difficulty in swallowing, which could be attributed to the involvement of the bulbar muscles. This disability was further aggravated by the head drop caused by the neck muscle weakness. The remaining four patients had difficulty in swallowing with the neck in an acutely flexed posture, and this was fully corrected by supporting the chin with the hand. None of the patients had difficulty in breathing at any time during the course of the illness.

The other neurological deficits were mild neck flexor weakness in five patients, bulbar or tongue involvement, and upper and lower motor neurone signs in the limbs in all. Proximal muscle wasting and weakness of varying severity of the upper limbs was noted in addition to distal muscle involvement in all the patients. In three patients the proximal muscles were severely involved, suggesting "flail limb" syndrome. The mean duration of illness at the last outpatient visit was 2.9 (2.6) years (range 1 to 9). Eight of the patients were ambulant and 
Table 1 Clinical features in nine patients with amyotrophic lateral sclerosis and neck extensor weakness

\begin{tabular}{|c|c|c|c|c|c|c|c|c|c|c|c|c|}
\hline \multirow[b]{3}{*}{ No } & \multirow{3}{*}{$\begin{array}{l}\text { Age } \\
\text { (years) }\end{array}$} & \multirow[b]{3}{*}{ Sex } & \multirow{3}{*}{$\begin{array}{l}\text { Involvement at } \\
\text { onset }\end{array}$} & \multirow{3}{*}{$\begin{array}{l}\text { Interval to } \\
\text { development of } \\
\text { head drop }\end{array}$} & \multicolumn{7}{|c|}{ Features in addition to head drop } & \multirow{3}{*}{$\begin{array}{l}\text { Duration of } \\
\text { - illness at las } \\
\text { follow up }\end{array}$} \\
\hline & & & & & \multirow{2}{*}{$\begin{array}{l}\text { Neck } \\
\text { flexors }\end{array}$} & \multirow[b]{2}{*}{ Bulbar } & \multirow[b]{2}{*}{ Tongue } & \multirow{2}{*}{$\begin{array}{l}\text { Release } \\
\text { reflexes }\end{array}$} & \multirow{2}{*}{$\begin{array}{l}\text { Jaw } \\
\text { jerk }\end{array}$} & \multicolumn{2}{|c|}{$\mathrm{UMN}+\mathrm{LMN}$} & \\
\hline & & & & & & & & & & UL & LL & \\
\hline 1 & 55 & $M$ & RUL & $2 y$ & - & + & + & + & + & + & + & 2 y $6 \mathrm{~m}$ \\
\hline 2 & 35 & $\mathrm{~F}$ & $4 \mathrm{Ls}$ & $9 \mathrm{~m}$ & - & + & + & + & - & + & + & $1 y$ \\
\hline 3 & 64 & $\mathrm{~F}$ & Dysarthria & 3 y $9 \mathrm{~m}$ & - & + & + & + & - & + & + & $4 y$ \\
\hline 4 & 50 & $M$ & UL & $5 \mathrm{~m}$ & $\mathrm{mw}$ & + & + & + & + & + & + & $1 y$ \\
\hline 5 & 42 & $M$ & $4 \mathrm{Ls}$ & $8 y$ & $\mathrm{mw}$ & - & + & + & + & + & + & $9 y$ \\
\hline 6 & 62 & $M$ & LL & $8 \mathrm{~m}$ & $\mathrm{mw}$ & + & + & + & + & + & + & $1 y$ \\
\hline 7 & 65 & $M$ & RUL & 1 y $9 \mathrm{~m}$ & $\mathrm{mw}$ & + & + & + & + & + & + & $2 y$ \\
\hline 8 & 49 & $\mathrm{~F}$ & RUL & 3 y $9 \mathrm{~m}$ & - & - & + & - & - & + & + & $4 y$ \\
\hline 9 & 58 & $M$ & LL & $3 \mathrm{~m}$ & $\mathrm{mw}$ & - & + & + & + & + & + & $2 y$ \\
\hline
\end{tabular}

F, female; LL, lower limb; LMN, lower motor neurone; Ls, limbs; m, month; M, male; mw, mild weakness; RUL, right upper limb; UL, upper limb; UMN, upper motor neurone; $y$, year.

one (case 2) was bed ridden. Five of the eight ambulant patients were partially dependent on others for their activities of daily living.

In addition to the well recognised aspects of management of ALS, these patients with head drop had two specific problems which needed special attention: difficulty in swallowing and social embarrassment. All the patients were advised to support their chin with the left hand while eating. Most Indians use the right hand to mix food and do not generally use a fork, knife, or spoon. As mentioned above, in four of the patients swallowing was normalised by correcting the neck posture, while in the other five, although there was improvement, mild to moderate dysphagia caused by involvement of the bulbar muscles persisted. All the patients were advised to wear a cervical collar, which significantly improved neck posture and social interaction. The men wore the typical Indian dress consisting of a long shirt and dhoti (a cloth worn round the lower trunk and lower limbs with pleats), and a folded cloth round the neck (angavastram) which was conveniently used to mask the cervical collar, while the women used the hanging end of the saree (pallav), thus avoiding social embarrassment. These simple techniques helped in boosting their morale and self esteem.

Illustrative case reports of head drop of early onset (case 4) and late onset (case 5) are described below.
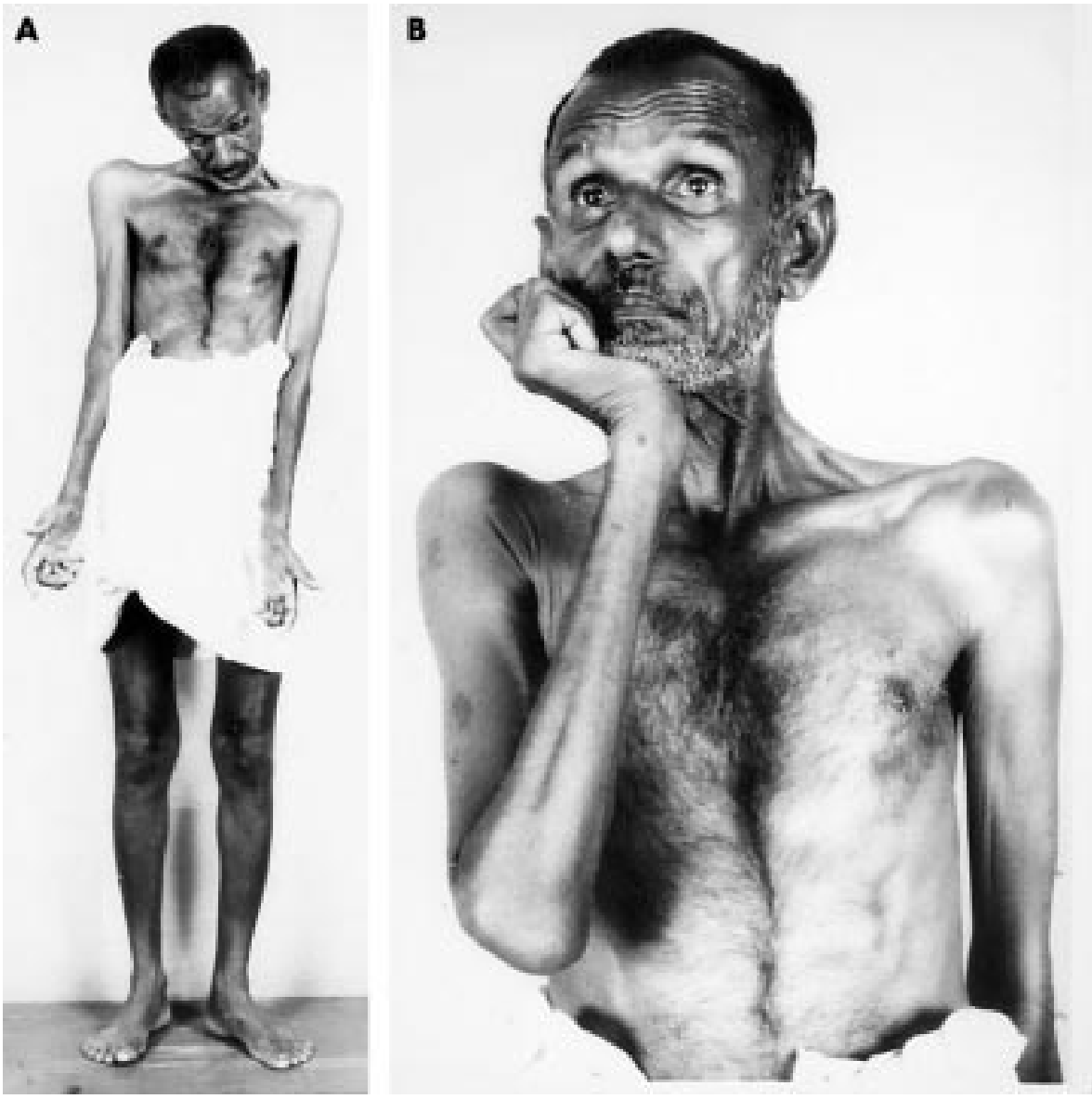

Figure 1 Case 4: 50 year old man who noted drooping of the head (A) five months after the onset of illness. Severe wasting and weakness of the hands is seen. (B) Characteristic posture, with chin supported by right hand (reproduced with permission). 


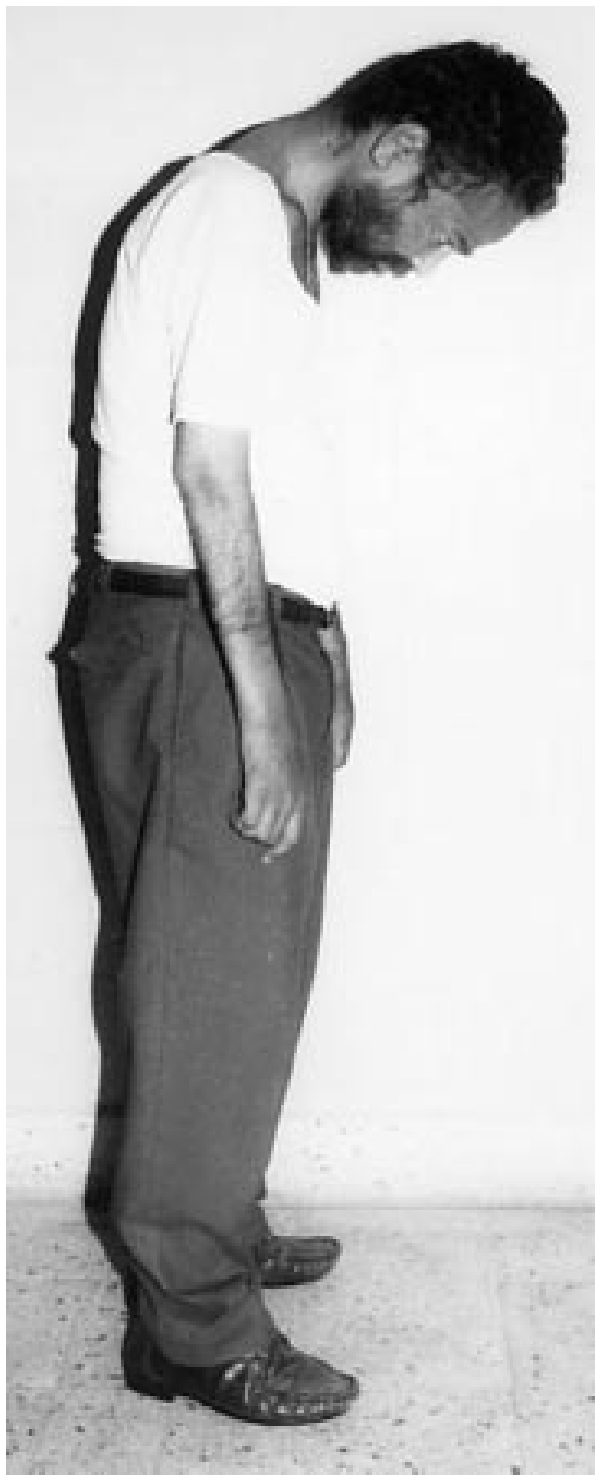

Figure 2 Case 5: 42 year old man with head drop which appeared eight years after the onset of his illness (reproduced with permission).

\section{Early onset of head drop (case 4)}

A 50 year old agriculturist was seen in March 1997. He presented with fasciculations and weakness of the left upper limb of one year duration, followed by the right lower limb a month later. Subsequently, wasting of both hands was noticed. Drooping of the head began about five months after the onset of the illness. The patient had difficulty in holding his head erect and had to support his chin with a hand to sustain normal head posture (fig 1). Three to four months later he developed progressive dysarthria and dysphagia. Fasciculations and wasting of the tongue and a brisk jaw jerk were present. Weakness of extensor muscles of the neck, generalised wasting and weakness of distal and proximal muscles of the upper limbs (distal muscles being more severely affected), and fasciculations were prominent features. There was mild wasting and weakness of the distal muscles of the lower limbs, but minimal in the proximal muscles. Tendon jerks were normal in the upper limbs and exaggerated in the lower limbs. Electromyography showed fibrillations and fasciculation potentials, large motor units with long duration, a decrease in motor units, and an incomplete recruitment pattern in the distal and proximal muscles of all limbs. Motor and sensory conduction studies were normal and there was no evidence of conduction block. He was ambulant but partially dependent for daily activities. He was advised to support his chin while eating and to wear a cervical collar to improve the posture.

Late onset of head drop (case 5)

A 42 year old machine operator was admitted in February 2002 with a slowly progressive illness over nine years. In 1993 he noted fasciculations of the limbs which was followed three years later by weakness and wasting of the distal muscles of the left upper limb, progressing to involve the proximal muscles. In 1997 he had difficulty in walking owing to weakness of the left lower limb. At this stage he was seen at the outpatient services of this institution and admission was advised, but he did not agree to this. During the next two years the right upper limb and later the right lower limb also became involved, the weakness being asymmetrical with the left limbs being more severely affected than the right. Eight years after the onset of symptoms he noticed head drop (fig 2 ) and had to support his chin with a hand to maintain the posture of his head. There were no bulbar symptoms.

Examination showed severe weakness of the extensors and mild weakness of the flexors of the neck. His tongue was mildly atrophied with fasciculations. There was severe wasting and weakness (MRC grade 1-2) of the distal and proximal muscles of the upper limbs with prominent fasciculations. There was mild to moderate wasting, weakness, and fasciculations of the lower limb muscles with bilateral foot drop. Deep tendon reflexes were exaggerated in all the limbs and the plantar responses could not be elicited. Electromyography showed widespread evidence of active denervation (fibrillations and fasciculations), dropout of motor units, large amplitude long duration motor unit potentials, and a decreased recruitment pattern. These changes were seen in the distal and proximal muscles of all limbs. Motor and sensory conduction studies were normal and there was no evidence of conduction block. Although the patient could not use his upper limbs, he was fully ambulant, with the characteristic head drop. He felt comfortable with the Philadelphia collar, which improved his swallowing difficulty and social embarrassment.

\section{DISCUSSION}

In ALS the initial symptoms are usually localised to the limbs or bulbar muscles. Neck and trunk muscle weakness is observed as the first symptom in $2 \%$ of patients with ALS $^{11}$ and neck flexion weakness is typically seen ${ }^{8}$; neck extensor muscle weakness with head drop has been reported in a few patients..$^{8-10}$ In a series of 12 patients with floppy head syndrome, Lange et al reported that three had ALS. ' Katz et al report that 12 of 790 new patients evaluated in a neuromuscular clinic had neck extensor weakness with head drop, and only one of these was diagnosed as ALS. ${ }^{8}$ In a small series of three cases presenting with extensor neck muscle weakness, Petiot et al reported that one was diagnosed as having ALS. ${ }^{10}$ In all these five patients the diagnosis of ALS was evident on clinical and electromyographic assessment.

In our series of 683 patients with ALS seen over 20 years, dropped head syndrome was observed in nine, constituting $1.3 \%$ of the whole group and suggesting that this syndrome is indeed a rare feature in ALS. Dropped head syndrome was found to be an early feature in the majority of cases. Five of the nine patients also had mild weakness of the neck flexors, in addition to the severe neck extensor weakness. As head drop was seen in all nine patients on a background of involvement of bulbar or limb muscles, there was no difficulty in establishing the cause of the neck extensor weakness. If this syndrome had occurred either as an initial presenting symptom or as an isolated feature, the differential diagnosis would have included myasthenia gravis, ${ }^{1}$ polymyositis, ${ }^{2}$ facio-scapulohumeral dystrophy, ${ }^{4}$ non-specific myopathy, ${ }^{78}$ chronic inflammatory demyelinating polyneuropathy, ${ }^{12}$ adult onset nemaline 
Table 2 Classification of "dropped head syndrome"

(A) Myogenic
Myasthenia gravis
Polymyositis $^{2}$
Isolated neck extensor myopathy ${ }^{78}$
Facio-scapulo-humeral muscular dystrophy ${ }^{4}$
Nemaline myopathy
Proximal myotonic myopathy ${ }^{13}$
Inclusion body myositis ${ }^{14}$
Carnitine deficiency
Adult onset acid maltase deficiency ${ }^{15}$
Acute hypokalaemic myopathy ${ }^{16}$
Congenital myopathy ${ }^{17}$
Focal myositis of extensor neck muscles ${ }^{18}$

(B) Neurogenic

Amyotrophic lateral sclerosis ${ }^{3}$ 8-10

Spinal muscular atrophy ${ }^{3}$

Chronic inflammatory demyelinating polyneuropathy ${ }^{12}$

(C) Miscellaneous

Hypothyroidism ${ }^{19}$

Cervical dystonia ${ }^{20}$

(D) Local causes

Cervical spondylosis with neurogenic weakness of neck extensors ${ }^{20}$ Ankylosing spondylitis ${ }^{20}$

myopathy, ${ }^{5}$ or proximal myotonic myopathy. ${ }^{13}$ A proposed classification of dropped head syndrome is shown in table 2. Essentially the syndrome could be myogenic, neurogenic, or caused by local abnormalities or other miscellaneous disorders such as hypothyroidism. ${ }^{13}$

In ALS the head drop can be attributed to the preferential involvement of anterior horn cells innervating the paraspinal muscles. Patients with dropped head syndrome are unable to lift their chin off the chest wall and find difficulty in looking forward while walking, talking, or eating, using their hands to support their chin. The head drop not only causes significant disability but is also a source of social embarrassment. Our patients were advised to wear a cervical collar and to mask the collar by incorporating minor modifications in their style of dressing, taking advantage of the Indian style of dress for men and women.

Dropped head syndrome caused by non-specific myopathy is a relatively benign condition with a non-progressive course. However, other neuromuscular disorders with dropped head syndrome are progressive and may even have a grave prognosis, as with ALS.

\section{Authors' affiliations}

M Gourie-Devi, A Nalini, S Sandhya, Department of Neurology, National Institute of Mental Health and Neurosciences, Bangalore, India

Competing interests: none declared

Correspondence to: Dr M Gourie-Devi, Flat 9, Doctors Apartments, Vasundhara Enclave, Delhi 110 096, India; gouriedevi@yahoo.co.in

Received 17 August 2002

In revised form 29 November 2002

Accepted 29 November 2002

\section{REFERENCES}

1 Grob D, Brunner NG, Namba T. The natural course of myasthenia gravis and effect of therapeutic measures. Ann NY Acad Sci 1981;377:652-69.

2 DeVere R, Bradley WG. Polymyositis: its presentation, morbidity and mortality. Brain 1975;98:637-66.

3 Ringel SP. Clinical presentations in neuromuscular disease. In: Vinken PJ, Bruyn GW, eds. Handbook of clinical neurology. New York: Elsevier, 1979:295-348.

4 Padberg GW, Lunt PW, Koch M, et al. Diagnostic criteria for facioscapulohumeral muscular dystrophy. Neuromusc Disord $1991 ; 1: 231-4$

5 Lomen-Hoerth C, Simmons ML, DeArmond SJ, et al. Adult-onset nemaline myopathy: another cause of dropped head. Muscle Nerve 1999;22: $1146-50$

6 Karpati G, Carpenter S, Engel AG, et al. The syndrome of systemic carnitine deficiency: clinical, morphologic, biochemical and pathophysiologic features. Neurology 1975;25:16-24.

7 Suarez GA, Kelly JJ. The dropped head syndrome. Neurology 1992;42:1625-7.

8 Katz JS, Wolfe Gl, Burns DK, et al. Isolated neck extensor myopathy: a common cause of dropped head syndrome. Neurology 1996:46:917-21.

9 Lange DJ, Fetell MR, Lovelace RE, et al. The floppy head syndrome. Ann Neurol 1986;20:133.

10 Petiot P, Vial C, de Saint Victor JF, et al. Dropped head syndrome: diagnostic discussion apropos of 3 cases. Rev Neurol (Paris) 1997; 153:251-5.

11 Jokelainen M. Amyotrophic lateral sclerosis in Finland. Acta Neurol Scand 1977;56:194-204.

12 Hoffman D, Gutmann L. The dropped head syndrome with chronic inflammatory demyelinating polyneuropathy. Muscle Nerve 1994;17:808-10.

13 Evidente VGH, Cook A. Floppy head syndrome resulting from proximal myotonic dystrophy. Ann Neurol 1997;42:417.

14 Hund E, Heckl R, Goebel HH, et al. Inclusion body myositis presenting with isolated erector spinae paresis. Neurology 1995:45:993-4.

15 Trend PS, Wiles CM, Spencer GT, et al. Acid maltase deficiency in adults. Diagnosis and management in five cases. Brain 1985; 108:845-60.

16 Bleck TP. Dropped head syndrome. Neurology 1993;43:846.

17 Riggs JE, Bodensteiner JB, Schochet SS. The dropped head sign: an unusual presentation of congenital myopathy. J Child Neurol 1994:9:330-1.

18 Biran I, Cohen O, Diment J, et al. Focal, steroid responsive myositis causing dropped head syndrome. Muscle Nerve 1999;22:769-71.

19 Askmark H, Olsson Y, Rossitti S. Treatable dropped head syndrome in hypothyroidism. Neurology 2000;55:896-7.

20 Swash $M$. Dropped-head and bent-spine syndrome; axial myopathies? Lancet 1998;352:758. 